\title{
Cohort study of hepatotoxicity associated with nimesulide and other non-steroidal anti-inflammatory drugs
}

Giuseppe Traversa, Clara Bianchi, Roberto Da Cas, Iosief Abraha, Francesca Menniti-Ippolito, Mauro Venegoni

Department of
Epidemiology,
National Institute of
Health, Viale
Regina Elena 299,
00161 Rome, Italy
Giuseppe Traversa
senior epidemiologist
Clara Bianchi
statistician
Roberto Da Cas
data manager
Francesca
Menniti-Ippolito
senior epidemiologist
Regional Health
Authority of the
Umbria Region,
06124 Perugia, Italy
Iosief Abraha
epidemiologist
Department of
Internal Medicine,
Fatebenefratelli
Hospital, 20121
Milan, Italy
Mauro Venegoni
head
Correspondence to:
G Traversa
giuseppe.traversa@
iss.it

BMJ 2003;327:18-22

\begin{abstract}
Objective To estimate the risk of acute hepatotoxicity associated with nimesulide compared with other non-steroidal anti-inflammatory drugs.

Design Retrospective cohort and nested case-control study.

Setting Umbria region, Italy.

Participants 400000 current, recent, and past users (almost 2 million prescriptions) of non-steroidal anti-inflammatory drugs between 1 January 1997 and 31 December 2001.

Main outcome measures Admissions to hospital for acute non-viral hepatitis and incidence of all hepatopathies and liver injury among users of nimesulide and other non-steroidal anti-inflammatory drugs.

Results Current use of non-steroidal

anti-inflammatory drugs was associated with a 1.4 (95\% confidence interval 1.0 to 2.1 ) increased risk of hepatopathy compared with past use. In current users of nimesulide the rate ratio for all hepatopathies and more severe liver injury was 1.3 (0.7 to 2.3$)$ and 1.9 (1.1 to 3.8), respectively.

Conclusion The risk of liver injury in patients taking nimesulide and other non-steroidal anti-inflammatory drugs is small.
\end{abstract}

\section{Introduction}

Nimesulide, a non-steroidal anti-inflammatory drug, is marketed in more than 50 countries. In March 2002, Finland suspended the marketing of nimesulide because of an associated high frequency of hepatotoxicity. ${ }^{1}$ Spain followed in May 2002, but not other European countries, such as Italy and France. ${ }^{2-5}$ Nimesulide is the most prescribed non-steroidal anti-inflammatory drug in Italy and Portugal, with Italy accounting for half the worldwide market. We compared the incidence of acute hepatotoxicity associated with nimesulide and other non-steroidal anti-inflammatory drugs.

\section{Methods}

During 1997-2001 we carried out a retrospective cohort study in the Umbria region of Italy, with a population of around 835000 . Patients were enrolled if they had received at least one prescription for a nonsteroidal anti-inflammatory drug within the national health service between 1 January 1997 and 31 December 2001. (The monitoring system that provided the information on use included only prescriptions issued within the health service; private purchase is therefore not captured in the cohort). In Italy most commonly prescribed non-steroidal anti-inflammatory drugs are also available as over the counter products-for example, diclofenac, ketoprofen, piroxicam, naproxen, ibuprofen-but prescription only non-steroidal antiinflammatory drugs are often purchased privately.

Drug use was defined as current according to the duration of the prescription (in defined daily doses) plus two weeks; recent for the 90 days after the end of the current period; and past use for the days up to 12 months after the prescription date. If a new prescription of the same drug occurred during the current period, time of use continued to accumulate in the particular category. When different non-steroidal anti-inflammatory drugs were dispensed in consecutive overlapping intervals of current use, time after the new prescription was allocated to the mixed use category.

Potential cases were all admissions to hospital for acute non-viral hepatitis. Codes were retrieved for main or secondary diagnoses according to ICD-9 (international classification of diseases, 9th revision) from the regional archive of hospital discharges: hepatitis, unspecified (573.3), acute and subacute necrosis of liver (570), other specified disorders of biliary tract (576.8), other specified disorders of liver (573.8), unspecified disorders of liver (573.9). No information was available on patients admitted to hospital outside the Umbria region.

Information on medical history, concomitant clinical conditions, drug use during the six weeks before admission, and laboratory data were collected from the clinical records, blinded to exposure status. Patients were excluded if they had malignancies, viral or chronic hepatitis, lithiasis of common biliary tract, a cholecystectomy performed during the admission to hospital included in the study, or normal liver function.

Abnormal liver function was defined as any increase between the upper limit of normal range and twice the upper limit of normal for alanine aminotransferase, aspartate aminotransferase, alkaline phosphatase, or total or conjugated bilirubin. Liver injury was defined as the increase over twice the upper limit of normal for alanine aminotransferase or conjugated bilirubin, or a combined increase of aspartate aminotransferase, alkaline phosphatase, and total bilirubin, provided one of them was above twice the upper limit of normal. ${ }^{6-8}$ To also include more severe cases we restricted the analysis to increases over five times the upper limit of normal. Information on liver tests was available for all cases.

A nested case-control study was carried out to control for potential confounders: use of any other drug (different from non-steroidal anti-inflammatory drugs) during the 30 days before admission and number of prescriptions for non-steroidal anti-inflammatory drugs during the current period (one and more than one packet). For each case we randomly selected 20 controls from the cohort, matched for sex and age (difference of one year). The date of admission for cases was the index date for the matched controls. Use of 
non-steroidal anti-inflammatory drugs at the index date for both cases and controls was defined as current, recent, or past, as in the cohort analysis.

Incidence was calculated by dividing the number of cases in each category of use by the corresponding person years of non-steroidal anti-inflammatory drug use. Poisson regression was used to control for the confounding effect of age and sex in the cohort study. Conditional logistic regression was used for the analysis of the case-control study. The analysis was performed with SAS (version 8.00) and SPSS (version 10.0.7) software.

\section{Results}

Between 1997 and 2001 around 2 million prescriptions for non-steroidal anti-inflammatory drugs were issued within the national health service in Italy and were included in our study. Nimesulide was the most prescribed drug (551000 prescriptions). The characteristics of users of the different non-steroidal anti-inflammatory drugs were similar (table 1). Most of the prescriptions were related to short term treatment (1.2 packets per prescription for nimesulide and 1.3 for other non-steroidal anti-inflammatory drugs).

The 397537 participants who received at least one prescription for a non-steroidal anti-inflammatory drug contributed to more than 770000 person years (current use, 141000 person years; recent use, 254000 person years; past use, 378000 person years; see table 1).

We excluded 168 of $819(20.5 \%)$ potential cases because of hepatopathy as a secondary diagnosis and concomitant malignancy (figure). Of the remaining 651 clinical records, $568(87.3 \%)$ were retrieved. Non-retrieved potential cases $(12.7 \%)$ were proportionally distributed over the study drugs. In total, 392 patients were excluded.

Forty two of the 176 cases of hepatopathy included in the final analysis occurred during current use of a non-steroidal anti-inflammatory drug (incidence 29.8 per 100000 person years). Compared with the incidence for past use (18.2), we estimated a rate ratio (adjusted for age and sex) of 1.4 (95\% confidence interval 1.0 to 2.1 ). This ratio increased among elderly participants: after taking into account the effect of sex and current use of non-steroidal anti-inflammatory drugs, those aged over 75 had a 5.7 -fold increase in the risk of hepatopathy compared with people under 45 . The risk of hepatopathy in males was increased by 1.5 (1.2 to 2.2) compared with females (table 2).

The risk of hepatopathy among current users of nimesulide was slightly higher than for other non-steroidal anti-inflammatory drugs (rate ratio 1.3 , 0.7 to 2.3$)$. When the analysis was restricted to patients with liver injury this ratio was 1.7 (0.9 to 3.3$)$. When only more severe diagnoses were included in the analysis, the rate ratio among users of nimesulide was 1.9 (1.1 to 3.8 ; table 3 ). For use of individual non-steroidal anti-inflammatory drugs compared with past use, the increase in the incidence of liver injury was 2.2 (1.3 to 3.9) for nimesulide and 1.5 (0.7 to 3.2) for diclofenac, the second most prescribed nonsteroidal anti-inflammatory drug (table 4). The number of events for individual non-steroidal anti-
Table 1 Characteristics of users of non-steroidal anti-inflammatory drugs (NSAIDs) and details of prescriptions, Umbria region, 1997-2001

\begin{tabular}{lccc} 
Characteristic & Nimesulide & Other NSAID & Any NSAID \\
\hline No of users* & 187312 & 341554 & 397537 \\
\hline Median age & 61 & 62 & 61 \\
\hline Male to female ratio $\dagger$ & $0.7: 1$ & $0.8: 1$ & $0.8: 1$ \\
\hline No of prescriptions & 551000 & 1400000 & 1951000 \\
\hline No of packets & 636000 & 1857000 & 2492000 \\
\hline Defined daily dose & 9535000 & 24998000 & 34533000 \\
\hline No of prescriptions per user & 2.9 & 2.2 & 2.4 \\
\hline No of packets per prescription & 1.2 & 1.3 & 1.2 \\
\hline Current use (person years): & & & 122711 \\
\hline Single & 38300 & 84411 & 18125 \\
\hline Mixed & 9994 & 18125 & 140836 \\
\hline Total & 48294 & 102536 & \\
\hline
\end{tabular}

*129 334 participants received a prescription for both nimesulide and other NSAID (concomitantly (mixed use) or in different time periods). Person time of mixed use of nimesulide also contributes to person time of mixed use of other NSAID.

tRatios of users of single NSAIDs are similar. However, ratio is higher when NSAIDs are taken as group (with or without nimesulide) because females received more NSAIDs (different substances) than males and thus contribute less in total group than in partially overlapping subgroups.

inflammatory drugs was too small to allow for comparison of risks.

The analysis carried out in the nested case-control study confirmed the risk estimates of the cohort analysis. The odds ratio of liver injury developing among users of nimesulide compared with users of other nonsteroidal anti-inflammatory drugs was 1.9 (0.6 to 5.6), after controlling for prescriptions of other drugs received in the 30 days before admission to hospital (index date) and for number of prescriptions for nonsteroidal anti-inflammatory drugs. Those who received drugs during the 30 days had a twofold increased risk (adjusted odds ratio 2.0, 0.6 to 6.6). No effect was associated with number of prescriptions for non-steroidal anti-inflammatory drugs during the current period $(0.7,0.3$ to 1.9$)$.

Among current users, the median interval between prescription for a non-steroidal anti-inflammatory drug and admission to hospital was 11 days, and only two of the 42 patients took the drugs for more than

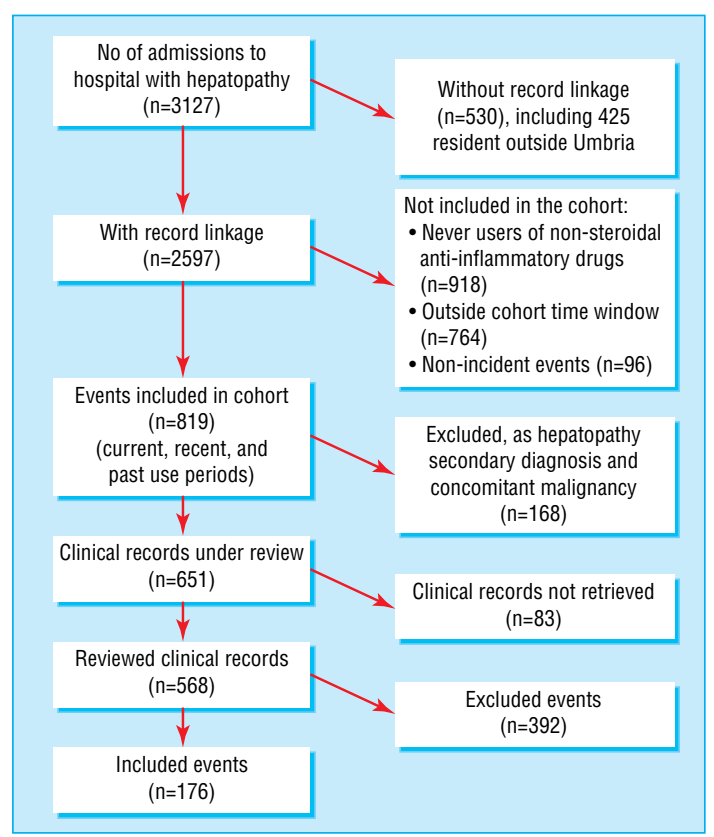

Flow of participants through trial 
Table 2 Incidence of admissions to hospital for hepatopathy, and rate ratios according to drug use, age, and sex

\begin{tabular}{|c|c|c|c|c|c|c|c|}
\hline \multirow[b]{2}{*}{ Characteristic } & \multirow[b]{2}{*}{ Person years } & \multicolumn{3}{|c|}{ All hepatopathies } & \multicolumn{3}{|c|}{ Liver injury } \\
\hline & & $\begin{array}{l}\text { No of } \\
\text { events }\end{array}$ & $\begin{array}{c}\text { Rates per } 100000 \\
\text { person years }\end{array}$ & $\begin{array}{c}\text { Adjusted rate ratio* } \\
(95 \% \mathrm{Cl})\end{array}$ & $\begin{array}{l}\text { No of } \\
\text { events }\end{array}$ & $\begin{array}{c}\text { Rates per } 100000 \\
\text { person years }\end{array}$ & $\begin{array}{c}\text { Adjusted rate ratio* } \\
(95 \% \mathrm{Cl})\end{array}$ \\
\hline \multicolumn{8}{|c|}{ Category of use: } \\
\hline Current & 140836 & 42 & 29.8 & $1.4(1.0$ to 2.1$)$ & 33 & 23.4 & $1.4(0.9$ to 2.1$)$ \\
\hline Recent & 254467 & 65 & 25.5 & 1.4 (1.0 to 2.0$)$ & 46 & 18.1 & $1.3(0.9$ to 1.9$)$ \\
\hline Past & 378433 & 69 & 18.2 & 1 & 56 & 14.8 & 1 \\
\hline \multicolumn{8}{|l|}{ Age (years): } \\
\hline$<45$ & 150849 & 11 & 7.3 & 1 & 9 & 6.0 & 1 \\
\hline $45-54$ & 127284 & 14 & 11.0 & 1.5 (0.7 to 1.3$)$ & 10 & 7.9 & 1.3 (0.7 to 3.3$)$ \\
\hline $55-64$ & 156046 & 41 & 26.3 & 3.6 (1.9 to 7.4$)$ & 29 & 18.6 & 3.1 (1.5 to 6.6$)$ \\
\hline $65-74$ & 192993 & 45 & 23.3 & $3.2(1.6$ to 6.1$)$ & 34 & 17.6 & 2.9 (1.4 to 6.1$)$ \\
\hline$\geqslant 75$ & 146542 & 65 & 44.4 & 5.7 (3.0 to 11.0$)$ & 53 & 36.2 & 5.6 (2.8 to 11.0$)$ \\
\hline \multicolumn{8}{|l|}{ Sex: } \\
\hline Male & 311531 & 88 & 28.2 & 1.5 (1.2 to 2.2$)$ & 68 & 21.8 & 1.7 (1.2 to 2.3 ) \\
\hline Female & 462182 & 88 & 19.0 & 1 & 67 & 14.5 & 1 \\
\hline
\end{tabular}

${ }^{*}$ Rate ratios for non-steroidal anti-inflammatory drug use adjusted for age and sex; rate ratios for age adjusted for sex and current use of non-steroidal anti-inflammatory drug; rate ratios for sex adjusted for age and current use of non-steroidal anti-inflammatory drug.

60 days. No fulminant hepatitis was observed. Among patients with liver injury a trend towards the normalisation of liver function (a positive dechallenge) could be assessed in 12 users of nimesulide $(75 \%)$ and in 13 users of other non-steroidal anti-inflammatory drugs $(65 \%)$. In the remaining patients there was either no follow up information or the length of stay was too small for comparisons (inconclusive dechallenge) (table 5)

Some patients admitted to hospital for liver injury received one or more prescriptions for the same drug after discharge: eight $(50 \%)$ for current users of nimesulide (either alone or mixed use) and five (25\%) for current users of other non-steroidal antiinflammatory drugs. No participants were readmitted to hospital.

Three deaths occurred among current users (diclofenac, nimesulide, and piroxicam). Cause of death was considered unrelated to liver injury: one patient had normalisation of liver function and the other two had cardiac failure, but no worsening of hepatopathy.

Table 3 Incidence of admissions to hospital for hepatopathy, and rate ratios among current users of nimesulide and other non-steroidal anti-inflammatory drugs by severity of hepatopathy

\begin{tabular}{|c|c|c|c|}
\hline Events & No of events* & $\begin{array}{c}\text { Rate per } 100000 \\
\text { person years } \dagger\end{array}$ & $\begin{array}{c}\text { Adjusted rate ratioł } \\
(95 \% \mathrm{Cl})\end{array}$ \\
\hline \multicolumn{4}{|l|}{ All hepatopathies $(n=42)$} \\
\hline Nimesulide & 17 & 35.2 & $1.3(0.7$ to 2.3$)$ \\
\hline $\begin{array}{l}\text { Other non-steroidal } \\
\text { anti-inflammatory drugs }\end{array}$ & 29 & 28.3 & 1 \\
\hline \multicolumn{4}{|l|}{ Liver injury $(n=33) \S$} \\
\hline Nimesulide & 16 & 33.1 & $1.7(0.9$ to 3.3$)$ \\
\hline $\begin{array}{l}\text { Other non-steroidal } \\
\text { anti-inflammatory drugs }\end{array}$ & 20 & 19.5 & 1 \\
\hline \multicolumn{4}{|c|}{ More severe liver injury $(n=28) \uparrow$} \\
\hline Nimesulide & 14 & 29.0 & $1.9(1.1$ to 3.8$)$ \\
\hline $\begin{array}{l}\text { Other non-steroidal } \\
\text { anti-inflammatory drugs }\end{array}$ & 16 & 15.6 & 1 \\
\hline
\end{tabular}

\section{All hepatopathies includes abnormal liver function and liver injury.}

*Patients who received both nimesulide and other non-steroidal anti-inflammatory drugs during current period (mixed use) are counted in both groups.

†Person years of exposure to nimesulide and other non-steroidal anti-inflammatory drugs are 48294 and 102536 , respectively.

$\ddagger$ Adjusted for age and sex.

§Twice upper limit of normal range

१Five times upper limit of normal range

\section{Discussion}

The risk of hepatopathy among patients taking non-steroidal anti-inflammatory drug is small. Despite its withdrawal in Finland and Spain because of reported hepatotoxicity, nimesulide was associated with only a small increased risk. The main risk factor for hepatotoxicity is age.

One strength of our study was that we followed a general population, in which almost 2 million prescriptions for non-steroidal anti-inflammatory drugs were issued during a five year period. Limitations of our study were that drug use was estimated through a prescription monitoring system, and no information was available on the actual use of the drugs, such as indications and dosage. A proxy for this information was the number of packets prescribed and the defined daily dose for each user. It seems that both nimesulide and other non-steroidal antiinflammatory drugs are used as short term treatments. It is possible that confounding by indication may play a part in our study. The indications for prescription within the Italian national health service are the same for nimesulide and other non-steroidal antiinflammatory drugs. Moreover, the users of both nimesulide and other non-steroidal anti-inflammatory drugs were similar, inferred from age, sex, expected duration of prescription, and concomitant prescriptions.

Our findings are consistent with available evidence. A cohort study in Canada concerned 1.5 million prescriptions for non-steroidal anti-inflammatory drugs. ${ }^{9}$ In our study, 16 current users of non-steroidal anti-inflammatory drugs were admitted to hospital for acute liver injury, which corresponds to a rate of 9 per 100000 person years and 1 per 100000 prescriptions. We found a high incidence of hepatopathy, but if the number of prescriptions is taken as the denominator, the incidence of liver injury is 1.7 per 100000 prescriptions, similar to the Canadian study.

The largest study to date is based on 2.1 million prescriptions for non-steroidal anti-inflammatory drugs from British general practitioners. ${ }^{10}$ Out of the 23 patients with acute liver injury (1.1 per 100000 prescriptions), eight were admitted to hospital (0.4 per $100000)$. The age range of the 23 cases was between 
Table 4 Incidence of admission to hospital for hepatopathies and for liver injury, and rate ratios, among current users of non-steroidal anti-inflammatory drugs*

\begin{tabular}{|c|c|c|c|c|c|c|c|}
\hline \multirow[b]{2}{*}{ Drug } & \multirow[b]{2}{*}{$\begin{array}{l}\text { Current use } \\
\text { (person years) }\end{array}$} & \multicolumn{3}{|c|}{ All hepatopathies } & \multicolumn{3}{|c|}{ Liver injury } \\
\hline & & $\begin{array}{l}\text { No of } \\
\text { events }\end{array}$ & $\begin{array}{c}\text { Rates per } 100000 \\
\text { person years }\end{array}$ & $\begin{array}{c}\text { Crude rate ratios } \\
(95 \% \mathrm{Cl})\end{array}$ & $\begin{array}{l}\text { No of } \\
\text { events }\end{array}$ & $\begin{array}{c}\text { Rates per } 100000 \\
\text { person years }\end{array}$ & $\begin{array}{c}\text { Crude rate ratios } \\
(95 \% \mathrm{Cl})\end{array}$ \\
\hline Nimesulide & 48294 & 17 & 35.2 & 1.9 (1.1 to 3.3$)$ & 16 & 33.1 & 2.2 (1.3 to 3.9$)$ \\
\hline Diclofenac & 35760 & 14 & 39.2 & 2.1 (1.2 to 3.8$)$ & 8 & 22.4 & 1.5 (0.7 to 3.2$)$ \\
\hline Piroxicam & 22051 & 5 & 22.7 & $1.2(0.5$ to 3.1$)$ & 4 & 13.6 & $1.2(0.4$ to 3.4$)$ \\
\hline Ketoprofen & 19848 & 5 & 25.2 & $1.4(0.6$ to 3.4$)$ & 4 & 20.2 & $1.4(0.5$ to 3.8$)$ \\
\hline Ketorolac & 5992 & 4 & 66.8 & 3.7 (1.3 to 10.0$)$ & 2 & 33.4 & 2.3 (0.6 to 9.2 ) \\
\hline Ibuprofen & 4482 & 2 & 44.6 & $2.4(0.6$ to 10.0$)$ & 2 & 44.6 & $3.0(0.7$ to 12.4$)$ \\
\hline Naproxen & 7833 & 2 & 25.5 & $1.4(0.3$ to 5.7$)$ & 1 & 12.8 & 0.9 (0.1 to 6.2$)$ \\
\hline Celecoxib & 6619 & 1 & 15.1 & 0.8 (0.1 to 6.6$)$ & 1 & 15.1 & $1.0(0.1$ to 7.3$)$ \\
\hline Meloxicam & 4232 & 1 & 23.6 & $1.3(0.2$ to 8.1$)$ & - & - & - \\
\hline Cinnoxicam & 1541 & 1 & 64.9 & 3.6 (0.2 to 12.5$)$ & 1 & 64.9 & $4.4(0.3$ to 13.7$)$ \\
\hline Flurbiprofen & 1022 & 1 & 97.8 & $5.4(0.3$ to 14.9$)$ & 1 & 97.8 & $6.6(0.3$ to 13.4$)$ \\
\hline Past use & 378433 & 69 & 18.2 & 1.0 & 56 & 14.8 & 1.0 \\
\hline
\end{tabular}

${ }^{*}$ Non-steroidal anti-inflammatory drugs with at least one event among current users shown.

Patients who received more than one non-steroidal anti-inflammatory drug during current period (mixed use) are included in counts of each subsequent drug.

26 and 80 , whereas the age range of our patients was between 27 and 96 , with almost $50 \%$ of the patients older than 80 .

In Finland, spontaneous reporting of adverse effects associated with nimesulide reached more than 100 per 100000 person years. The corresponding incidence for other non-steroidal anti-inflammatory drugs was less than 1 per 100000 person years. In Spain, nimesulide was associated with the highest spontaneous reporting rate for hepatopathy (9.37 cases per million packets). ${ }^{3}$ A large variability in reporting rates for other non-steroidal antiinflammatory drugs has been observed, which is often the case with spontaneous reporting systems.

We found only a small increase in the risk associated with nimesulide, consistent with observations in other countries, such as Italy, France, and Portugal. In these countries the reporting of hepatotoxicity was similar for nimesulide and other non-steroidal anti-inflammatory drugs.

The potential mechanism of hepatotoxicity associated with nimesulide is unknown. It has been suggested that symptomatic hepatic effects of most non-steroidal anti-inflammatory drugs are usually mild. ${ }^{11}$ In most of the patients in our study admitted to hospital because

Table 5 Characteristics of patients with liver injury among current users of non-steroidal anti-inflammatory drugs

(NSAIDs). Values are numbers (percentages) of patients unless stated otherwise

\begin{tabular}{lcc} 
Characteristic & Nimesulide $\mathbf{(} \mathbf{n} \mathbf{1 6})$ & Other NSAIDs $\mathbf{( n = 2 0 )}$ \\
\hline Median age & 79 & 69 \\
\hline Male to female ratio & $7: 9$ & $9: 11$ \\
\hline $\begin{array}{l}\text { Other drugs (30 days before } \\
\text { admission) }\end{array}$ & $14(87)$ & $15(75)$ \\
\hline \begin{tabular}{l} 
Median ratio*: \\
\hline Alanine aminotransferase
\end{tabular} & 4.4 & 5.1 \\
\hline $\begin{array}{l}\text { Median alkaline } \\
\text { phosphatase }\end{array}$ & 2.8 & 1.6 \\
\hline Dechallenge† (positive) & $12(75)$ & $13(65)$ \\
\hline Dechallenge (inconclusive) & $4(25)$ & $7(35)$ \\
\hline Rechallenge & $8(50)$ & $5(25)$ \\
\hline Deaths & $1(6)$ & $2(8)$ \\
\hline
\end{tabular}

Three patients who received both nimesulide and other NSAIDs during the current period (mixed use) are counted in both groups. In six patients the liver injury was hepatocellular, in 13 it was cholestatic, and in 14 it was mixed. ${ }^{6}$

*Ratio between maximum value and upper normal limits.

†Normalisation of liver function before discharge.

\section{What is already known on this topic}

Liver injury is a rare class effect of non-steroidal anti-inflammatory drugs

An increased risk of hepatotoxicity with nimesulide was suggested by spontaneous reports

A procedure has been set up in Europe for the re-evaluation of the risk profile of nimesulide

\section{What this study adds}

The risk of hepatopathy among patients taking non-steroidal anti-inflammatory drugs, including nimesulide, is small

of liver injury, there was evidence of a trend towards the normalisation of liver function. As with two other studies, no fulminant hepatitis was observed. ${ }^{45}$ This suggests that some of the spontaneously reported cases of fulminant hepatitis attributed to non-steroidal anti-inflammatory drugs are linked to concomitant conditions that would lead to exclusions in epidemiological studies.

A final consideration is the need to evaluate the overall risk profile of non-steroidal anti-inflammatory drugs, particularly the risk of serious gastroduodenal complications (bleeding and perforation), which are almost 10 times higher than hepatotoxicity. The incidence of admission to hospital for bleeding or perforation among non-users of non-steroidal antiinflammatory drugs is around 100 events per 100000 persons per year. Among users of non-steroidal anti-inflammatory drugs, assuming a relative risk of 4 , around 400 events per 100000 persons per year are expected, with around 300 extra cases per 100000 persons per year. ${ }^{12}{ }^{13}$ In three observational studies in Italy, nimesulide was generally of average to low risk and other non-steroidal anti-inflammatory drugs, such as ketorolac and piroxicam, were more gastrotoxic..$^{14-16}$

Our study was coordinated by the Istituto Superiore di Sanità, the scientific body of the Italian National Health Service. We thank Paolo Di Loreto, Barbara Gamboni, Carlo Romagnoli, and Mariangela Rossi (Umbria Regional Health Authority) for providing the information on hospital admissions and drug use in Umbria; the NHS staff who helped to retrieve the clinical 
records; Antonella Germani for reviewing the clinical records; Bruno Caffari, Marina Maggini, Alfonso Mele, Roberto Raschetti, Stefania Spila Alegiani, Tommaso Stroffolini, Nicola Vanacore (Istituto Superiore di Sanità), Achille Caputi (University of Messina), and Albano Del Favero (University of Perugia) who participated in the discussion and review of the study protocol and the study findings; and Sara Modigliani for editorial support.

Contributors: All authors contributed to designing the study, interpreting the results, and writing the paper. GT will act as guarantor for the paper.

Funding: Expenses were covered by NHS funds. The study was partly supported by research funds from the Ministry of Health and the Umbria Regional Health Authority.

Competing interests: None declared.

1 National Agency for Medicine (Finland). www.nam.fi/english/news/ press_releases/nimed.html (accessed 16 June 2003).

Agencia Espanola del Medicamento. www.msc.es/agemed/csmh/notas/ nimesulida asp (accessed 16 June 2003).

Macia MA, Carvajal A, Garcia del Pozo J, Vera E, del Pino A. Hepatotoxicity associated with nimesulide: data from the Spanish pharmacovigilance system Clin Pharmacol Ther 2002·79:596-7.

4 Conforti A, Leone R, Moretti U, Mozzo F, Velo G. Adverse drug reactions related to the use of NSAIDs with a focus on nimesulide. Results from spontaneous reporting from a northern Italian area. Drug Safet 2001;24:1081-90

Agence Francaise de Securité Sanitaire des Produits de Santé agmed.sante.gouv.fr (accessed 16 June 2003).

International Consensus Meeting. Criteria of drug-induced liver disorders. J Epatol 1990;11:272-6.
7 Danan G. Liver test abnormalities. In: Bénichou C, ed. Adverse drug reactions. A practical guide to diagnosis and management. Chichester: Wiley, 1994 Danan G, Bénichou C. Causality assessment of adverse reactions to drugs: I. A novel method based on the conclusions of international consensus meetings: application to drug-induced liver injuries. J Clin Epidemiol 1993;46:1323-30.

9 García-Rodríguez LA, Pérez Gutthann S, Walker AM, Lueck L. The role of non-steroidal anti-inflammatory drugs in acute liver injury. $B M J$ 1992;305:865-8.

10 García-Rodríguez LA, Williams R, Derby LE, Dean AD, Jick H. Acute liver injury associated with nonsteroidal anti-inflammatory drugs and the role of risk factors. Arch Intern Med 1994:154.311-6.

11 Walker AM. Quantitative studies of the risk of serious hepatic injury in persons using nonsteroidal antiinflammatory drugs. Arthritis Rheum 1997:40:201-8.

12 Hernandez-Diaz S, García-Rodríguez LA. Epidemiologic assessment of the safety of conventional nonsteroidal anti-inflammatory drugs. $A m \mathrm{~J}$ Med 2001;110:20-7S

13 Hernandez-Diaz S, García-Rodríguez LA. Association between nonsteroidal anti-inflammatory drugs and upper gastrointestinal tract bleeding/ perforation. An overview of epidemiologic studies published in the 1990s. Arch Intern Med 2000;160:2093-9.

14 García-Rodríguez LA, Cattaruzzi G, Troncon MG, Agostinis L. Risk of hospitalisation for upper gastrointestinal tract bleeding associased with kepithe nists, and or a

15 Menniti-Ippolito F, Maggini M, Raschetti R, Da Cas R, Traversa G, Walker AM. Ketorolac use in outpatients and gastrointestinal hospitalization: a comparison with other non-steroidal anti-inflammatory drugs in Italy. Eur J Clin Pharmacol 1998;54:393-7.

16 Traversa G, Walker AM, Menniti-Ippolito F, Caffari B, Capurso L, Dezi A, et al. Gastroduodenal toxicity of different NSAIDs: a case-control study in the province of Rome. Epidemiology 1995;6:49-54.

(Accepted 16 June 2003)

\section{Prospective observational cohort study of time saved by prehospital thrombolysis for ST elevation myocardial infarction delivered by paramedics}

David K Pedley, Kim Bissett, Elizabeth M Connolly, Carol G Goodman, Ian Golding, T H Pringle, G P McNeill, S D Pringle, M C Jones

Ninewells Hospital and Medical School, Dundee DD1 9SY David K Pedley specialist registrar accident and emergency

Kim Bissett audit nurse, chest pain service

Elizabeth M

Connolly

nurse practitioner,

chest pain service

Carol G Goodman

clinical group

manager, medicine

and cardiovascula

group

T H Pringle

consultant

cardiologist

G P McNeill

consultant

cardiologist

S D Pringle

consultant

cardiologist

M C Jones

consultant in acut

medicine

continued over

BMJ 2003;327:22-6

\section{Abstract}

Objectives To evaluate a system of prehospital thrombolysis, delivered by paramedics, in meeting the national service framework's targets for the management of acute myocardial infarction. Design Prospective observational cohort study comparing patients with suspected acute myocardial infarction considered for thrombolysis in the prehospital environment with patients treated in hospital.

Setting The catchment area of a large teaching hospital, including urban and rural areas. Participants 201 patients presenting concurrently over a 12 month period who had changes to the electrocardiogram that were diagnostic of acute myocardial infarction or who received thrombolysis for suspected acute myocardial infarction.

Main outcome measures Time from first medical contact to initiation of thrombolysis (call to needle time), number of patients given thrombolysis appropriately, and all cause mortality in hospital. Results The median call to needle time for patients treated before arriving in hospital $(\mathrm{n}=28)$ was $52(95 \%$ confidence interval 41 to 62) minutes. Patients from similar rural areas who were treated in hospital $(n=43)$ had a median time of 125 (104 to 140) minutes. This represents a median time saved of 73 minutes $(\mathrm{P}<0.001)$. Sixty minutes after medical contact $64 \%$ of patients $(18 / 28)$ treated before arrival in hospital had received thrombolysis; this compares with $4 \%$ of patients $(2 / 43)$ in a cohort from similar areas. Median call to needle time for patients from urban areas $(\mathrm{n}=107)$ was 80 (78 to 93$)$ minutes. Myocardial infarction was confirmed in $89 \%$ of patients $(25 / 28)$ who had received prehospital thrombolysis; this compares with $92 \%(138 / 150)$ in the two groups of patients receiving thrombolysis in hospital.

Conclusions Thrombolysis delivered by paramedics with support from the base hospital can meet the national targets for early thrombolysis. The system has been shown to work well and can be introduced without delay.

\section{Introduction}

Evidence of the benefits of early thrombolysis in the context of an acute myocardial infarction is overwhelming. ${ }^{1234}$ This is reflected in the national service framework for coronary heart disease in the adoption of a challenging standard "call to needle time" (from the initial call for help to treatment) of less than 60 minutes. $^{5}$ 